\title{
Goal Programming as a Decision Tool FOR NeW Products PlanNing: \\ A Case Example
}

\author{
Ed Timmerman \\ University of Tennessee at Martin \\ Martin, Tennessee \\ James A. Petty \\ Abilene Christian University \\ Abilene, Texas
}

Applications of goal programming (GP) to marketing decision environments have been relatively rare, even though its composition makes GP eminently suitable for many marketing contexts. It appears that the technique could be particularly helpful in industries that specialize in advancing new technologies where marketing efforts are constantly undertaken in uncharted waters. The practical meaning of goal programming, for an industry dealing with new products designed for new markets and marketed in unfamiliar settings, is that this technique would aid in the generation of more rational product introduction decisions.

The purpose of this article is to present and illustrate the use of goal programming as an aid to making common product introduction decisions, especially where technologically innovative products are concerned. First, is a description of the origin and primary elements of the linear goal programming, then a demonstration of how the tool can be applied to media choice and planning, and finally the procedure is utilized in a promising industry (cellular communication) which is fraught with problems introduced by the accelerating advances in technology and ever shortening product life cycles.

\section{Background}

The concept of the profit maximizer, in classical economic theory, provides neither a sufficiently descriptive nor prescriptive model for the decision maker in a contemporary organizational setting. Since a broad range of goal categories may exist, including economic, social, ethical, and political ones, as well as multiple elements within each category, it is hopeless to think of treating these in a linear fashion or to compare these at the same priority level.

In this context, the decision maker is not trying to maximize, but to "satisfice." $\mathrm{He}$ is positioned as one attempting to attain a set of goals in an environment. The primary difficulty in decision analysis is the treatment of these multiple conflicting objectives. The task becomes one of value trades in the social structure of conflicting interests.

Journal of Business Strategies, Volume 6, Number 1 (Spring 1989) 
Goal programming, a modification and extension of linear programming, is a technique for handling decision problems by means of a prioritized solution to a system of multiple conflicting objectives. The product of goal programming is no substutute for a decision, but it does enable the one making the decision to be more systematic in attaining goals.

Charnes and Cooper [3], who were also pioneers in the application of linedr programming (LP), originated the concept of goal programming. The conventional LP method utilized unidimensional objective functions (usually the maximization of profits or the minimization of costs) which proved excessively limiting where complex decision environments were the norm. The GP model they developed would handle multiple goals in multiple dimensions, therefore yielding a more feasible solution.

Later Ijiri [7] contributed the notion of "preemptive priority factors" to allow treatment of multiple goals according to their importance, assigning weights to goals of the same priority level. His work refined the concept of goal programming and developed it as a distinct mathematical programming technique. Building upon this work, goal programming has found application in industrial and operations research settings, manpower and academic planning, management accounting, hospital administration, and inventory control.

Despite this foundation, applications of goal programming have been relatively scarce in the area of marketing. Exceptions to this occur in the areas of media planning ([4], [5], [11]), sales effort allocation [16], and in retail store selection modeling [12].

The practical use of the goal programming method has been considerably advanced by the work of three writers. Sang M. Lee's text of general applications for decision analysis [13] and a later management science text [14] have solidly installed the approach as a standard decision tool. J. P. Ignizio's writings in the area of operations research ([8], [9], [10]) have also given the concept valuable exposure. And Marc J. Schniederjans book on linear goal programming [17] is a practical and helpful aid for the first time user. The software available with this text is especially useful.

\section{The Goal Programming Method}

The goal programming model consists of three basic components: a mathematical expression of the weighted multiple goals to be achieved (objective function) the limitations or restrictions on achieving the desired goals (goal constraints), and the provision that negative solution values are not acceptable (non-negativity requirements). Using this approach, the algorithm seeks to minimize the deviations from each of a set of goals (objective criterion or function) subject to constraints imposed by the entire goal set (goal parameters or constraints imposed by limited resources, such as money, production capacity, time, etc., as restrictions on the ability to optimize the stated goals), rather than attempting to maximized or minimize an objective function directly. Additionally, there is an implicit requirement that all decision variables take on non-negative values. This is appropriate for most marketing problems since they tend to deal with discrete variables. 
The most critical phase of the application of goal programming is the formulation of the model for the problem under consideration. In fact, considering the current availability of GP software, solution is not generally much of a difficulty once the model is constructed. Formulation of the model includes the following procedural elements:

1. Determine and specify whether the problem is one of maximization or minimization (as a rule, if the problem focuses on profit it is a maximization problem, or it on cost, it is a minimization problem).

2. Identify and define all factors relevant to the choice (decision variables) along with the amount each of these factors affect a decision (contribution coefficients).

3. State the goal (objective function) for the decision problem.

4. Identify and list the various constraints (also known as side constraints) working against the accomplishments of the goal. This usually shows up as limits on resource availability or resource usage.

5. Indicate that the resulting values of the decision cannot be negative by setting each of the decision variables equal to or greater than zero.

The formulation for a media decision case will take the general form of a maximization problem. ${ }^{1}$

This goal mathematical programming procedure converges on an optimum solution within the constraints of the business environment. A critical difference in the GP approach and that of simple linear programming is that GP allows for a convex solution (i.e., one that expresses diminishing returns) which is much more realistic in most marketing contexts than a mere straight line solution. Complex problems are invariably multidimensional.

${ }^{1}$ Goal Programming Format for a Maximization Problem

$$
\begin{array}{lll}
\text { Maximize: } & Z=\sum_{j=1}^{J} c_{j} x_{j} \quad \text { (objective function) } \\
\text { subject to: } \quad \sum_{j=1}^{J} a_{i j} x_{j} \gtreqless b_{i} \quad \text { (goal constraints) }
\end{array}
$$$$
\text { and: } \quad x_{j} \geq 0 \quad \text { (non-negativity requirement) }
$$

where:

$$
\begin{aligned}
& Z=\text { value to be maximized } b_{i}=\text { right-hand-side values } \\
& C_{j}=\text { contribution coefficients } I=\text { number of side constraints } \\
& x_{j}=\text { decision variables } J=\text { number of decision variables } \\
& a_{i j}=\text { technological coefficients }
\end{aligned}
$$




\section{The New Technology Environment}

Product innovation and introductions into the marketplace are occurring at an ever increasing rate. The consequences of this for successful marketing planning and strategy formulation are complicated by the ever shortening average length of product life cycles [16]. Consider that, layered on top of this, new product introductions are becoming more expensive and the chanced of succeeding with them are less than in previous years. Taken all together, these facts suggest that marketers of product innovations ought to be using the best and most efficient methods for selecting approaches to introduction, particularly in anticipation that the moment of strategic fit between the competencies of the business and the critical success factors in a market will quickly pass.

The fast pace that revolutions in technology have set for business, highlights the relevance of the "strategic window" analogy [1]. When the "fit" between the competencies of the organization and market requirements are at an optimum for only brief spaces, it is essential that the firm be able to move through that opening expeditiously.

One result of this environment is that the "better to be safe than sorry" market testing mentality of recent years is giving way, in some sectors, to an action posture as organizations adapt to a more dynamic marketplace. This calls for a streamlining of decision-making processes in order to more quickly respond to market opportunities. Speed and agility in assessing opportunities. Speed and agility in assessing opportunities in the marketplace is essential to expedite rapid entry. Moving at the earliest opening of the "window" avoids preemptive actions on the part of competitors.

The nature of this "new" environment emphasizes the value of tools which can improve the efficiency, as well as the effectiveness, of decisions related to how market entry should proceed. Goal programming is just such a tool.

\section{A Case in Point}

For several decades there has been a shortage of vehicular telephone service in many metropolitan areas. As recently as 1982 , only about one-tenth of $1 \%$ of all motor vehicles in the United States were equipped with mobile telephones, and long waiting lists for service existed in many areas [2]. Additionally, with the advent of citizens band radios (CBs) and cordless home telephones, the general population was becoming more familiar with, and more receptive to, the concept of portable communication.

To address this situation, the Federal Communications Commission (FCC) approved the establishment of a "domestic public cellular radio telecommunications service." The system is defined as a "high capacity land mobile system in which the spectrum assigned is divided into discrete channels. These channels are assigned in groups to small geographic cells covering a defined service area [6]." Two allocations are due to be licensed in each Standard Metropolitan Statistical Area (SMSA); one to a non-wireline common carrier (known as "radio common carriers"), and one to a wireline carrier. One June 7, 1982, the FCC accepted applications to provide cellular 
service in the 30 largest U.S. markets. Considerable interest was demonstrated at this filing and intense competition for the smaller markets is in evidence.

One of those in contention for this market activity is Mobile Phone of Texas, the largest mobile telephone and pager provider in the northern and western areas of that state. Mobile Phone is about 15 years old, but has developed into the best known and most reputable radio common carrier (RCC) in its marketplace. Eager to extend its operation into this potentially lucrative market, it has been a forerunner in preparing application materials and monitoring the selection process. In anticipation of receiving the RCC award in the standard Metropolitan Statistical Areas (SMSAs) in which it is filing, Mobile Phone is engaged in preparing a marketing plan.

A major obstacle to confident planning is Mobile Telephone's unfamiliarity with the potency of various media available for gaining exposure for the new cellular concept to the potential market. In the past the company has relied almost exclusively on yellow page and newspaper advertising, but feels that the cellular concept will require a more aggressive approach.

Lacking experience, how do they construct a media mix suitable to the task of introduction? One answer is to employ goal programming in the search for a suitable blend of media.

\section{Formulation of the Model}

In the inodel, a linear goal programming (LGP) model has been used in conjunction with separable programming (SP) for advertising media selection. Our model includes three levels of advertising each for television, radio, and newspaper (Table 1). These levels are typical of the options offered by the media available in the geographic area of application. As in the typical marketing situation, the rates of audience exposure per level are not linear. For instance, Level 1 of television advertising, which costs $\$ 300$, would yield 350 units of advertising exposure, while Level 2 , which costs $\$ 570$, would yield a 560 units of advertising exposure, and Level 3 , which costs $\$ 660$, would yield 660 units of advertising exposure. As established in this Table, each of the three media exhibit a diminishing marginal return of exposure.

Table 1

Linear Goal Programming Formulation

\begin{tabular}{|c|c|c|c|c|c|c|c|c|c|c|}
\hline \multirow{3}{*}{\begin{tabular}{|c|} 
Units of \\
Ad vertısing \\
Exposure
\end{tabular}} & \multicolumn{8}{|c|}{ Advertising Medium } & \multirow{3}{*}{$\begin{array}{c}\text { Deviations } \\
\text { From } \\
\text { Goal }\end{array}$} & \multirow{3}{*}{$\begin{array}{c}\text { Goal } \\
\text { Constraints }\end{array}$} \\
\hline & \multicolumn{2}{|c|}{ Television } & \multicolumn{2}{|r|}{ Radio } & \multirow{2}{*}{$R A D_{3}$} & \multirow{2}{*}{\multicolumn{3}{|c|}{$\begin{array}{c}\text { Newspaper } \\
P A P_{1} P A P_{2} P A P_{3}\end{array}$}} & & \\
\hline & $T V_{1} \quad T V_{2}$ & $T V_{3}$ & $R A D_{1}$ & $R A D_{2}$ & & & & & & \\
\hline Total Units & $350 \quad 560$ & 660 & 450 & 530 & 560 & 300 & 500 & 690 & $d_{1}-$ & 10,000 \\
\hline Television - Max & $350 \quad 560$ & 660 & & & & & & & $d_{2}+$ & 6,500 \\
\hline Radio - Max & & & 450 & 530 & 560 & & & & $\dot{d}_{3}+$ & 3,500 \\
\hline Newspaper - Min & & & & & & 330 & 500 & 690 & $d_{4}-$ & 2,000 \\
\hline Newspaper - Max & & & & & & $\mathbf{3 3 0}$ & 500 & 690 & $d_{5}+$ & 2,000 \\
\hline $\begin{array}{l}\text { Total Budget } \\
\text { Constraint }\end{array}$ & $\$ 300 \$ 570$ & $\$ 660$ & $\$ 240$ & $\$ 475$ & $\$ 520$ & $\$ 175$ & $\$ 300$ & $\$ 330$ & $d_{6}+$ & $\$ 7,500$ \\
\hline
\end{tabular}


The model seeks to minimize the deviations from the goals as stated in Table 1. Goals are subjectively established by the advertiser as are the priority weights. Specifically, the model seeks to minimize the following objective function:

$$
Z=W(1.2) P_{1}\left[d_{6}+\right]+W(1.1) P_{2}\left[d_{1}-\right]+W(1) P_{3}\left[d_{4}-\right]+W(1) P_{4}\left[\left(d_{2}+\right)+\left(d_{3}+\right)+\left(d_{5}+\right)\right]
$$

where:

$d_{1}$ - through $d_{6}-$ are the negative deviations from the goals as stated in Table 1; $d_{1}+$ through $d_{6}+$ are the positive deviations from the goals as stated in Table 1 ;

$P_{1}$ through $P_{5}$ are the priorities of minimizing the deviations from the stated goals; and

$W_{1}$ through $W_{5}$ are a weighting of the priorities.

This statement dictates that the first priority $\left(P_{1}\right)$ will be to minimize the amount to which the total budget constraint $\left(d_{6}\right)$ of $\$ 7,500$ is exceeded. This priority will carry a weight of 1.2 relative to other priorities. Of second importance $\left(P_{2}\right)$ is the minimization of any deviation below the goal of achieving 10,000 units of exposure to the advertising message by means of the total promotional scheme.

The third priority in order $\left(P_{3}\right)$ is to minimize the negative deviation from the goal of achieving 2,000 units of advertising exposure by means of the newspaper medium. The final priority is to minimize the positive deviations from the goals of achieving 6,500 units of exposure through the television medium, achieving 3,500 units of exposure through the medium of radio, and achieving 5,500 units of exposure through the medium of newspaper. Newspaper is the only medium for which both positive and negative deviations from the goal are a concern.

The objective function laid out above is minimized subject to the constraining goals in Table 1. These constraints are not necessarily, or even usually, absolute and therefore constitute a kind of wish list. Therefore the superordinate goal is to come as close as possible to achieving each goal given their assigned weights.

Table 2

\section{Linear Goal Programming Solution}

\begin{tabular}{|l|c|c|c|}
\hline \multirow{2}{*}{ Medium } & \multicolumn{3}{|c|}{ Levels of Advertising } \\
\cline { 2 - 4 } & $\begin{array}{c}\text { Level 1 } \\
\text { Units/Exposure/Cost }\end{array}$ & $\begin{array}{c}\text { Level } 2 \\
\text { Units/Exposure/Cost }\end{array}$ & $\begin{array}{c}\text { Level 3 } \\
\text { Units/Exposure/Cost }\end{array}$ \\
\hline Television & $15.13 / 5,296 / \$ 4,539$ & & $1.82 / 1,204 / \$ 1,204$ \\
\hline Radio & & & \\
\hline Newspaper & \multicolumn{3}{|c|}{ Exposure $=10,000 \quad$ Cost $=\$ 7,500$} \\
\hline Total & \multicolumn{3}{|c|}{} \\
\hline
\end{tabular}

As reported in Table 2, the result of this process is that an optimum solution exists where 15.13 units of exposure at television rate 1 (TV1), 1.82 units of exposure at television rate $3\left(T V_{3}\right), 3.33$ units of exposure at radio rate $1\left(R A D_{1}\right)$, and 2.89 units of exposure at newspaper rate $3\left(P A P_{3}\right)$ are employed. Since promotion cannot 
be purchased in fractional units and since a procedure of rounding these results to integers would, in this case, cause a budget overrun of only $\$ 30$, a whole-number solution is available which very nearly matches the intended overall goal of spending no more than $\$ 7,500$ while still achieving the intended exposure rates.

Even though a solution under a different set of constraints may indicate discontinuance or non-use of a particular medium (for example, newspaper), Mobile Phone of Texas may be wise to continue using that medium for the purpose of maintaining relationship or because the medium will be a major adopter of cellular units.

\section{Conclusions}

Developing and solving the goal programming model not only assists managers in making decisions, but it also points out the trade-offs which must occur due to limited resources and conflicts among goals. This information puts the manager more in touch with the realities of the business environment and, consequently, clarifies the true nature of relationships within that environment. Furthermore, the model allows the manager to review critically the priority structure for the goals in view of the solution derived by the model.

For the sake of simplicity, some aspects of advertising were not given specific consideration. For example, the time dimension (i.e., time intervals between exposures in the same medium, harmonized exposures in various media for special purposes, etc.), weighted exposure index of each medium for specific market segments (i.e., women, men, teen-age market, etc.), and advertising goals for certain time periods, products, and market segments have been ignored in this model. However, if such data are available, these can easily be incorporated into the model. It appears that goal programming has a great potential for advertising media selection and scheduling when there are multiple conflicting goals of the advertising campaign.

Much of the decision making process relies heavily on relevant managerial experience. When deprived of this valuable resource, as in the case of new technology marketing, a systematic method of applying what is known about the decision context is especially useful. Goal programming is such a technique and holds great promise for reducing the risk involved in a task more and more common to the marketer of this age.

\section{References}

1. Abell, Derek F. "Strategic Windows." Journal of Marketing, Vol. 42 (July, 1978), pp. 21-25.

2. Bain, John S., Winston E. Hinsworth, and Susannah B. Bristol. Cellular Mobile Radio Telecommunications Service: Applications for the Top 30 Markets. Lehman Brothers Kuhn Loeb Research (September, 1982), p. 1.

3. Charnes, Abraham, and W. W. Cooper. Management Models and Industrial Applications of Linear Programming. New York, NY: John Wiley (1961). 
4. Charnes, Abraham, W. W. Cooper, J. K. DeVoe, D. B. Learner, and W. Rejnecke. "A Goal Programming Model for Media Planning." Management Science, Vol. 14 (April, 1968), pp. 423-430.

5. de Kluyver, Cornelis A. "Hard and Soft Constraints in Media Scheduling." Journal of Advertising Research, Vol. 18 (June, 1978), pp. 27-31.

6. Federal Communications Commission. "Notice of Inquiry and Proposed Rulemaking." Cellular Communications Systems, Docket CC-79-318 (January, 1980).

7. Ijiri, Y. Management Goals and Accounting for Control. Chicago, IL: Rand McNally (1965).

8. Ignizio, J. P. "A Review of Goal Programming-Tool for Multiobjective Analysis." Journal of the Operational Research Society, Vol. 29 (November, 1978), pp. 11091119.

9. Ignizio, J. P. "An Approach to the Modeling and Analysis of Multiobjective Generalized Networks." European Journal of Operational Research, Vol. 12 (April, 1983), pp. 357-361.

10. Ignizio, J. P., and J. H. Perlis. "Sequential Linear Goal Programming: Implementation Via MXPS." Computers and Operations Research, Vol. 6 (October, 1979), pp. 141-145.

11. Keown, A. J., and C. P. Davis. "Integer Goal Programming in Advertising Media Selection." Decision Sciences, Vol. 10 (October, 1979), pp. 577-592.

12. Kim, C. Young. "A Manufacturer's Retail Store Selection Model in the Normative Distribution Channel Design: A Goal Programming Approach." Akron Business and Economic Review, Vol. 14 (October, 1983), pp. 41-47.

13. Lee, Sang M. Goal Programming for Decision Sciences. Philadelphia, PA: Auerback Publishers (1972).

14. Lee, Sang M. Introduction to Management Science. New York, NY: Dryden Press (1983).

15. Lee, Sang. M., and M. Bird. "Goal Programming Model for Sales Effort Allocation." Business Perspectives, Vol. 6 (July, 1970), pp. 17-21.

16. Qualls, William, Richard W. Olshavsky, and Ronald E. Michaels. "Shortening of the PLC-An Empirical Test." Journal of Marketing, Vol. 45 (October, 1981), pp. 76-80.

17. Schniederjans, Marc J. Linear Goal Programming. Princeton, NJ: Petrocelli (1984). 